ISSN 0103-9954

\title{
UTILIZAÇÃO DE EXTENSORES ALTERNATIVOS NA PRODUÇÃO DE COMPENSADOS MULTILAMINADOS
}

\section{USES OF ALTERNATIVE EXTENDERS FOR PLYWOOD MANUFACTURING}

\author{
Setsuo Iwakiri ${ }^{1}$ Alexsandro B. Cunha ${ }^{2}$ Carlos Eduardo C. Albuquerque ${ }^{3}$ \\ Elianice Gorniak $^{2}$ Lourival Marin Mendes ${ }^{3}$
}

\section{RESUMO}

Esta pesquisa foi desenvolvida com o objetivo de avaliar a potencialidade de uso de farinhas de soja, arroz, milho, aveia e mandioca, como extensores alternativos a farinha de trigo (testemunha) para produção de compensados. Foram produzidas 21 chapas com lâminas de madeira de Eucalyptus cloeziana, sendo três chapas por tratamento, utilizando a seguinte formulação em partes por peso: resina uréia-formaldeído - 100, extensor -75 , água -80 e catalisador -7 . Os resultados médios de resistência da linha de cola aos esforços de cizalhamento, pelo teste seco e úmido, demostraram que as farinhas de arroz e de aveia podem ser utilizados como extensor alternativo à farinha de trigo.

Palavras-chave: Extensor, uréia-formaldeído, compensado, Eucalyptus cloeziana.

\begin{abstract}
This research was developed aiming to evaluate the potentiality of soy bean, rice flour, maize flour, oatmeal and manioc flour, as alternative extenders to wheatmeal for plywood manufaturing. Twenty one boards were produced using Eucalyptus cloeziana venner, being three boards per treatment according to the following formulation in parts per wheight: urea-formaldheyde resin 100 , extender -75 , water -80 and catalyst -7 . The average values of shear bonding tests (dry and wet), showed that the ricemeal and oatmeal could be used as an alternative extender to the wheatmeal.
\end{abstract}

Key words: Extender, urea-formaldheyde resin, plywood, Eucalyptus cloeziana.

1. Engenheiro Florestal, Dr., Professor Titular do Departamento de Engenharia e Tecnologia Florestal, Universidade Federal do Paraná, Rua Bom Jesus, 650, CEP 80035-050, Curitiba (PR).

2. Aluno do Curso de Mestrado em Engenharia Florestal, Universidade Federal do Paraná, Rua Bom Jesus, 650, CEP 80035-050, Curitiba (PR).

3. Aluno do Curso de Doutorado em Engenharia Florestal, Universidade Federal do Paraná, Rua Bom Jesus, 650, CEP 80035-050, Curitiba (PR). 


\section{INTRODUÇÃO}

$\mathrm{Na}$ manufatura de produtos reconstituídos de madeira, o adesivo é um componente fundamental, tendo em vista ser responsável pela ligação entre as peças de madeira e a transferência de tensões geradas na linha de cola durante a sua utilização, além da participação significativa na composição de custos de produção.

No caso específico de painéis de madeira compensada, produzidos com resina uréiaformaldeído, o índice de qualidade e custo final do produto está condicionado ao grau de extensão na formulação do adesivo. O extensor é um componente adicionado na mistura e tem como função reduzir o custo final do adesivo, auxiliar no controle da viscosidade e nas funções de movimento do adesivo desde o espalhamento até a sua solidificação ou cura (MARRA, 1992; SELLERS, 1985).

Pela definição, os extensores são substâncias a base de amido e proteína que possuem alguma ação adesiva e, quando misturados na composição do adesivo a base de resina uréia-formaldeído, contribuem para melhorar as suas propriedades reológicas (MOREIRA, 1985). Segundo o Boletim Técnico da ALBA QUÍMICA (1990), a quantidade de extensor, no adesivo, pode variar de 25 a 125 partes por peso de sólidos da resina. Menor grau de extensão é recomendado para compensados destinados à exportação, com maior resistência à umidade ambiental e, maior grau de extensão destina-se aos chamados compensados de "caixaria" nos quais os índices técnicos exigidos são mais baixos.

No Brasil, as indústrias de compensados utilizam, como extensor, a farinha de trigo a qual, em grande parte, ainda é importada. Tendo em vista o volume significativo de consumo desse produto, considerado importante matéria-prima na produção de alimentos, vários estudos têm sido desenvolvidos no sentido de buscar materiais alternativos para a substituição do trigo como extensor na produção de compensados. Os materiais como farinhas de centeio, soja, milho, mandioca, sorgo, aveia, cevada, arroz, caroço de algodão, sangue de animais, batatas, entre outros, são mencionados por MOREIRA (1985), tendo alguns deles grande potencial de utilização.

De acôrdo com MARRA (1992) e BALDWIN (1981), as principais exigências para um material ser utilizado como extensor são:

- Ser de fácil dispersão em resinas líquidas, resultando numa mistura uniforme e mantendo sua viscosidade durante a aplicação.

- Melhorar a coesividade e capacidade de ligamento do adesivo, aumentando a sua vida útil.

- Auxiliar no espalhamento, evitando a ultrapassagem do adesivo pela superfície da lâmina externa e derramamento excessivo pelas bordas.

MOREIRA (1985) estudou a potencialidade de uso de farinhas provenientes de arroz, mandioca, milho, soja, batata inglesa, batata doce, sangue, polvilhos de mandioca e araruta, e a combinação deles na manufatura de compensados de Araucaria angustifolia. Os resultados do teste seco indicaram que, com exceção da combinação de farinha de mandioca e de milho, todos os demais tratamentos não apresentaram diferenças significativas em relação à testemunha (trigo). Quanto ao teste úmido, as combinações de farinha de mandioca e batata inglesa, farinha de arroz e 
batata doce, farinha de soja e polvilho de mandioca apresentaram índices de qualidade inferior ao determinado pelo Padrão PS-1-74 (1974). Portanto, muitos dos materiais estudados demonstraram certa potencialidade para uso como extensor na manufatura de painéis compensados.

O presente trabalho foi desenvolvido com o objetivo de avaliar a potencialidade de alguns materiais como extensor, em substituição à farinha de trigo, na produção de painéis compensados.

Os objetivos específicos foram:

- Produção de compensados com a utilização de extensores alternativos a farinha de trigo.

- Determinação da resistência da linha de cola aos esforços de cisalhamento pelo teste seco e úmido.

- Avaliação do comportamento dos extensores alternativos em relação à farinha de trigo.

\section{MATERIAIS E MÉTODOS}

\section{Materiais}

As lâminas de madeira, utilizadas nesta pesquisa, foram de Eucalyptus cloeziana, com 2,0mm de espessura, obtidas com base do desenrolamento de toras, provenientes da Floresta Estadual do Instituto Florestal de São Paulo, localizada no Município de Santa Bárbara do Rio Pardo.

Foi utilizada a resina uréia-formaldeído com viscosidade de $560 \mathrm{cP}, 53 \%$ de sólidos, e $\mathrm{pH}$ 8,0, catalisador a base de sulfato de amônia, e os seguintes extensores: farinha de trigo (testemunha), soja, arroz, milho, aveia e mandioca, adquiridos no comércio local, em razão do preço e disponibilidade.

\section{Metodologia}

As lâminas foram secas a um teor de umidade em torno de $10 \%$ e, posteriormente, seccionadas em dimensões finais do painel de 30 x $30 \mathrm{~cm}$.

$\mathrm{O}$ adesivo foi preparado de acordo com a seguinte formulação em partes por peso: resina (UF) -100 , extensor -75 , água -80 e catalisador -7 . Foram produzidos painéis trilaminados com gramatura de $320 \mathrm{~g} / \mathrm{m}^{2}$ por linha dupla de colagem. $\mathrm{O}$ ciclo de prensagem adotado foi: temperatura $=$ $100^{\circ} \mathrm{C}$, pressão $=15 \mathrm{kgf} / \mathrm{cm}^{2}$ e tempo de prensagem $=7$ minutos. Para cada tipo de extensor (tratamento) foram produzidos três painéis (repetições). Após a prensagem, os painéis foram esquadrejados e acondicionados na câmara de aclimatização à temperatura de $20^{\circ} \mathrm{C}$ e umidade relativa de $65 \%$, até atingir umidade de equilíbrio em torno de $12 \%$,

Dos três painéis de cada tratamento, foram retirados 24 corpos de prova para ensaios de resistência da linha de cola aos esforços de cizalhamento, sendo doze corpos de prova destinados ao teste seco (acondicionados) e doze para o teste úmido (após 24 horas de imersão em água). As dimensões dos corpos de prova e métodos de ensaios foram definidos de acordo com a norma ASTM D-805 (1982). 
Para análise estatística dos resultados, utilizou-se o delineamento inteiramente casualizado, com a análise de variância e teste de Tukey a 95\% de probabilidade.

\section{RESULTADOS E DICUSSÕES}

Os valores médios e desvio padrão da resistência da linha de cola, aos esforços de cizalhamento pelo teste seco, estão apresentados na Tabela 1.

TABELA 1: Resistência da linha de cola - teste seco.

\begin{tabular}{l|rrrr}
\hline Extensor & \multicolumn{3}{c|}{ Valores médios $\left(\mathrm{kgf} / \mathrm{cm}^{2}\right)$} & Desvio padrão $\left(\mathrm{kgf} / \mathrm{cm}^{2}\right)$ \\
\hline Mandioca & 27,36 & $\mathrm{a}$ & & 2,21 \\
Trigo & 25,33 & $\mathrm{a}$ & $\mathrm{b}$ & 2,23 \\
Aveia & 24,80 & $\mathrm{a}$ & $\mathrm{b}$ & 2,83 \\
Milho & 24,07 & $\mathrm{a}$ & $\mathrm{b}$ & 2,62 \\
Arroz & 23,49 & $\mathrm{~b}$ & 4,32 \\
Soja & 17,82 & \multicolumn{2}{c}{$\mathrm{c}$} & 3,59 \\
\hline
\end{tabular}

As médias seguidas da mesma letra são estatisticamente iguais, ao nível de 5\% de probabilidade de erro.

Os valores médios de resistência da linha de cola a seco variaram de 17,82 (soja) a $27,36 \mathrm{kgf} / \mathrm{cm}^{2}$ (mandioca), estando esses valores acima do valor médio de $17,6 \mathrm{kgf} / \mathrm{cm}^{2}$ de acordo com o padrão CS-35-61(1968). Isso significa que todos os extensores avaliados, neste estudo, comportaram-se satisfatoriamente em termos de resistência da linha de cola pelo teste seco. Com relação aos resultados publicados por outros pesquisadores, PIO (1996) obteve, para compensados de Eucalyptus scabra e Eucalyptus robusta, com colagem uréica e trigo como extensor, valores variando na faixa de 23,6 a $26,2 \mathrm{kgf} / \mathrm{cm}^{2}$, indicando que os resultados obtidos neste estudo podem ser considerados satisfatórios.

Na comparação dos valores médios de resistência da linha de cola entre os painéis produzidos com trigo (testemunha) como extensor e os demais tratamentos, apenas os painéis com extensor de soja apresentaram valor médio de resistência, estatisticamente, inferior em nível de probabilidade de 95\%. Portanto, os painéis produzidos com arroz, milho, aveia e mandioca, como extensor, apresentaram comportamento satisfatório em relação ao trigo.

Os valores médios e desvio padrão da resistência da linha de cola, aos esforços de cizalhamento para o teste úmido, estão apresentados na Tabela 2.

Os valores médios de resistência da linha de cola variaram de 1,08 (milho) a $14,89 \mathrm{kgf} / \mathrm{cm}^{2}$ (soja). Os menores valores foram obtidos para painéis produzidos com milho e mandioca como extensor, sendo estatisticamente inferiores em comparação aos demais tratamentos.

Os resultados obtidos foram inferiores ao valor médio de $17,6 \mathrm{kgf} / \mathrm{cm}^{2}$ de acordo com o padrão CS-35-61(1968), no entanto, um aspecto importante, a ser considerado, é de que os painéis, produzidos com extensores a base de farinha de soja, arroz e aveia, apresentaram valores médios de resistência da linha de cola, estatisticamente, iguais aos painéis produzidos com farinha de trigo. 
Como outro parâmetro referencial, os resultados obtidos por MOREIRA (1985), no teste úmido, foram na faixa de 12,06 a $16,85 \mathrm{kgf} / \mathrm{cm}^{2}$, para compensados produzidos com extensores a base de farinhas de trigo, mandioca, milho, arroz, e batata.

TABELA 2: Resistência da linha de cola - teste úmido.

\begin{tabular}{l|cc|c}
\hline Extensor & Valores médios $\left(\mathrm{kgf} / \mathrm{cm}^{2}\right)$ & Desvio padrão $\left(\mathrm{kgf} / \mathrm{cm}^{2}\right)$ \\
\hline Soja & 14,89 a & 2,42 \\
Aveia & 12,64 a & 1,74 \\
Trigo & 10,46 a b & 1,29 \\
Arroz & 8,63 b c & 4,57 \\
Mandioca & 5,27 & c & 0,48 \\
Milho & 1,08 & d & 0,21 \\
\hline
\end{tabular}

As médias seguidas da mesma letra são estatisticamente iguais, ao nível de 5\% de probabilidade de erro.

As diferenças na resistência da linha de cola entre o teste seco e úmido, podem ser melhor visualizadas através da Figura 1.

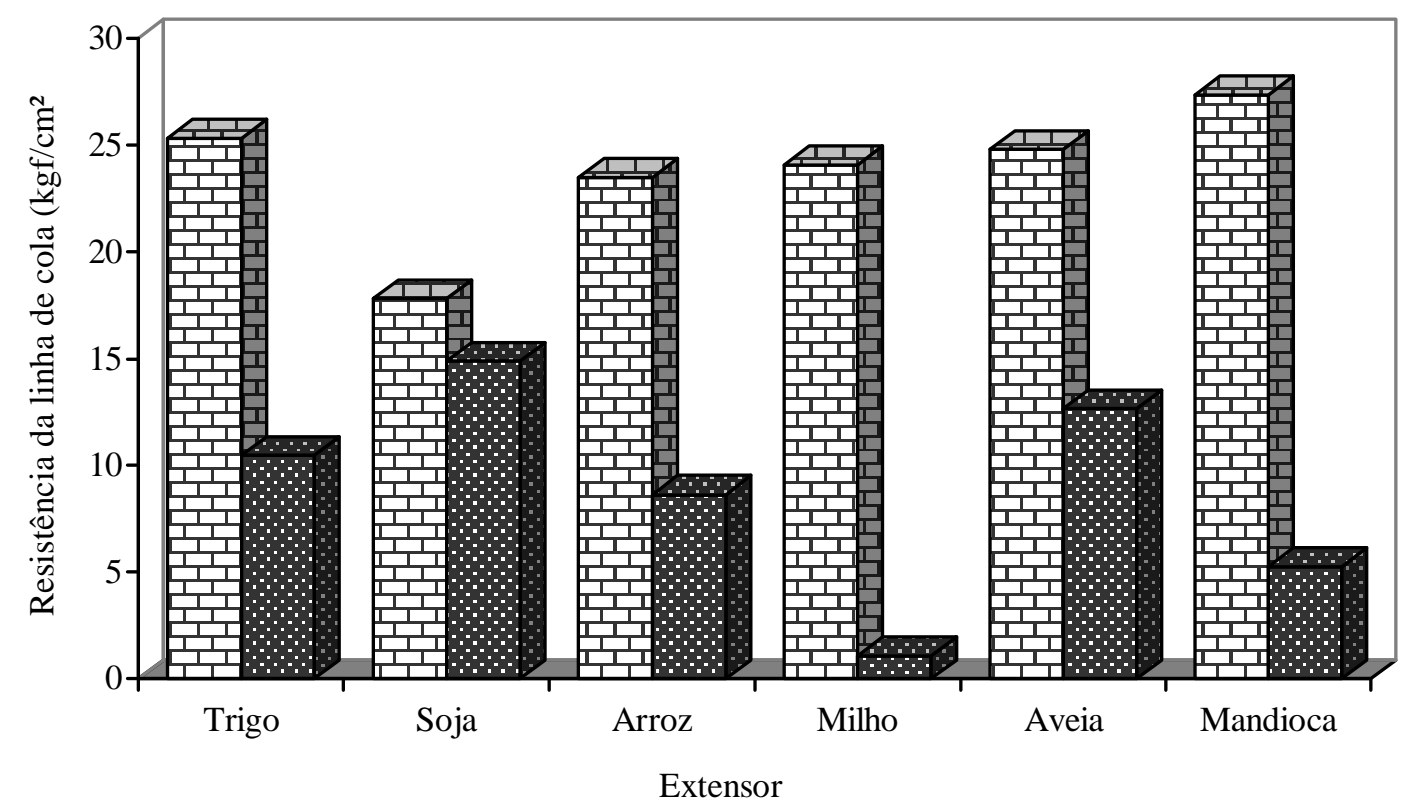

回 Seco $\mathbf{0}$ Úmido

FIGURA 1: Comparação entre os valores médios de resistência da linha de cola dos compensados nos testes seco e úmido.

Como se pode constatar, os painéis, produzidos com farinha de milho e mandioca como extensor, apresentam um comportamento, altamente diferenciado entre os testes seco e úmido. Provavelmente, essa diferença pode ter sido em conseqüência da alta capacidade de absorção de água e, consequentemente, poderá comprometer a sua utilização em ambientes de alta umidade 
relativa do ar.

Por outro lado, cabe ressaltar o comportamento dos painéis produzidos com a farinha de soja e de aveia os quais apresentaram tendências para maior resistência da linha de cola para o teste úmido, em relação à testemunha (farinha de trigo).

\section{CONCLUSÕES}

Com base nos resultados obtidos nesta pesquisa, as seguintes conclusões podem ser apresentadas:

- Todos os painéis, produzidos com diferentes tipos de extensores avaliados neste estudo, apresentaram valores médios de resistência da linha de cola pelo teste seco, superiores aos valores estabelecidos pelo padrão CS-35-61(1968);

- Os extensores, a base de farinha de arroz, milho, aveia e mandioca, apresentaram comportamento satisfatório em relação à farinha de trigo, podendo-se ressaltar a sua importância como extensores alternativos ao trigo, tendo em vista que parte desse material ainda é importada pelo País.

- Embora sendo inferiores, em relação ao padrão CS-35-61(1968), os painéis produzidos com extensor a base de farinha de soja, arroz e aveia, apresentaram valores médios de resistência da linha de cola pelo teste úmido, estatisticamente, iguais aos painéis produzidos com farinha de trigo.

- A farinha de milho e mandioca não se comportaram satisfatoriamente como extensor, apresentando alta absorção de água e baixa resistência da linha de cola em contacto direto com a água.

- $\mathrm{Na}$ análise conjunta dos testes seco e úmido, pode-se concluir que as farinhas de arroz e aveia foram os extensores que apresentaram melhor comportamento, tomando a farinha de trigo como parâmetro de referência.

\section{REFERÊNCIAS BIBLIOGRÁFICAS}

ALBA QUÍMICA. Boletim técnico: Ref: 15-09. 1990.

AMERICAN SOCIETY FOR TESTING AND MATERIALS. Testing venner, plywood and other glued veneer constructions. Philladelphia, 1982. (Annual Book of ASTM Standards, ASTM D805)

BALDWIN, R.F. Plywood manufacturing practices. San Francisco: Miller Freeman, 1995. 388p.

COMMERCIAL STANDARD C.S. 35-61. Hardwood plywood. 1968. 
MARRA, A. A. Technology of wood bonding: principles in practice. New York: Van Nostrand Reinhold, 1992. 453p.

MOREIRA, W.S. Extensores alternativos para produção de compensados com resina uréiaformaldeído. Curitiba: UFPR, 1985. 81p. Dissertação (Mestrado) - Universidade Federal do Paraná, 1985.

PIO, N.S. Avaliação da madeira de Eucalyptus scabra (Dum-Cours) e Eucalyptus robusta (Smith) na produção de painéis compensados. Curitiba: UFPR, 1996. 101p. Dissertação (Mestrado) - Universidade Federal do Paraná, 1996.

SELLERS JR., T. Plywood and adhesive technology. New York: Marcel Dekker, 1985. 661p.

U.S. PRODUCT STANDARD PS 1-74 - For Constructions \& industrial plywood with typical APA grade-trade marks, Product Standards Section, National Bureau of Standard, 1974. 33p. 